\title{
ESTUDO COMPARATIVO DA SENSIBILIDADE DAS TÉCNICAS DE IMUNOFLUORESCÊNCIA DIRETA, APLICADA A DECALQUES DE CÓRNEA E DE INOCULAÇÃO INTRACEREBRAL EM CAMUNDONGOS, A PARTIR DA SALIVA, PARA O DIAGNÓSTICO PRECOCE DA RAIVA EM BOVINOS.
}

\author{
J. A. CÔRTES * \\ M.R. NILSSON** \\ S.A. VASCONCELLOS***
}

RFMV - A/18

\begin{abstract}
CÔRTES, J.A.; NILSSON, M.R.; VASCONCELLOS, S.A. Estudo comparativo da sensibilidade das técnicas de imunofluorescência direta, aplicada a decalques de córnea e de inoculação intracerebral em camundongos, a partir da saliva, para diagnóstico precoce da raiva em bovinos. Rev. Fac. Med. vet. Zootec. Univ. S. Paulo, 15 (2):-143-50, 1978.

RESUMO: O exame dos 57 pares de amostras (córnea e saliva) tomadas, em dias sucessivos, de 18 bovinos com raiva experimental, revelou que, quando se empregou uma outra das técnicas utilizadas, a freqüência de reações positivas foi marcadamente diferente: $84.2 \%$ com a técnica de imunofluorescência direta aplicada a decalques de córnea e $22,8 \%$ com a de inoculaçāo intracerebral em camundongos a partir da saliva. Observou-se ainda que o teste de córnea uma vez positivo manteve sempre esta característica, condiçâo não verificada quando o material examinado foi a saliva; que em nenhum caso foi detectado vírus na saliva sem que se verificasse, para o mesmo animal, resultado positivo quando se empregou o teste de córnea; e que os valores falso-negativos apresentados pela técnica de imunofluorescência aplicada a decalques de córnea, da ordem de $16.7 \%$, indicam que resultados negativos não excluem a possibilidade da doença.
\end{abstract}

UNITERMOS: Raiva bovinos*; Córnea, teste*; Saliva, exame*

\section{INTRODUÇAO}

Conhecida desde a mais remota antigüidade, a raiva inclui-se entre as doenças que maiores temores infundem à humanidade, seja pelo êxito quase invariavelmente letal de sua evolução's, seja pela dramaticidade peculiar que acompanha os casos da doença, especialmente em seres humanos?.

A capacidade do seu agente causal parasitar elevado número de espécies de vertebrados favorece a sua persistência na natureza; e o empenho da ciência para bloquear a cadeia de transmissão do vírus sofre sérias limitações dependentes do hospedeiro considerado.

O mecanismo usual de transmissão - por contágio direto - é assegurado por diversos fatores, notadamente o hábito de morder de algumas espécies hospedeiras que eliminam o virus pela sali$\mathrm{Va}^{3}, 17,25,27$.

A despeito da existência de registros esparsos de recuperação espontânea em certas espécies animais ${ }^{16}$, a ciência não conta com meios para interromper o curso letal da doença. A medicina limita-

(*) Professor Livre Docente;

$\left(*^{*}\right)$ Pesquisador Científico do Instituto Biológico de São Paulo.

(***) Professor Assistente Doutor do Departamento de Medicina Veterinária Preventiva e Saúde Animal da Faculdade de Medicina Veterinária e Zootecnia da U.S.P. 
se usualmente, no caso do hospedeiro humano, à prevenção pós-exposição ao risco da infecção, baseada em penoso processo de imunização, de elevado custo e apreciável risco para o paciente ${ }^{26}$. A indicação desse tratamento representa, não raramente, sério dilema para o médico face à inexistência de elementos capazes de indicar, se por ocasião da exposição do suscetível ao risco da infecção, o animal mordedor, aparentemente sadio, era fonte de infecção $0^{2021,26}$.

A eliminação do vírus da raiva pela saliva de animais infectados tem sido verificada amplamente ${ }^{3: 11: 14,17,24,27}$, todavia, é importante estabelecer-se o momento a partir do qual este agente começa a ser eliminado por esta via.

Até recentemente, os recursos disponíveis para diagnóstico da raiva ${ }^{7,}, 21,28$ dependiam do exame de fragmentos do sistema nervoso central, colhidos após a morte do doente. Os resultados positivos, contudo, não permitiam assegurar se, no momento da exposição, havia ou não presença do vírus na saliva.

Com a aplicação da técnica de anticorpos fluorescentes ${ }^{7}$ a diferentes tecidos e secreções, têm surgido, nos últimos anos, numerosos procedimentos aplicáveis ao indivíduo ainda vivo para o diagnóstico da raiva.

VALLONE e cols. ${ }^{24}$ em 1966, trabalhando com seres humanos acometidos pela raiva, descreveram uma técnica diagnóstica pré-mortem da doença, utilizando esfregaços de sedimento de saliva.

SCHNEIDER ${ }^{20}$ (1969) utilizou técnica aplicável a decalques de córnea de camundongos vivos ou mortos.

SCHAAF e SCHAAL ${ }^{19}$ (1971) idealizaram o Nasentest e o Mundtest baseados na utilização de decalques, respectivamente, de mucosa nasal e bucal de diversas espécies animais.

SMITH e cols. ${ }^{23}$, em 1972, demonstraram in vivo a presença do antígeno rábico em fibras nervosas de secções congeladas da pele de camundongos, de cães e de raposas infectados com este vírus. BRYCESON e cols. ${ }^{5}$ (1975), utilizando o mesmo procedimento, descreveram o teste facial em seres humanos.
Dentre as técnicas utilizadas para detectar $o$ antigeno rábico em animais vivos, a de SCHNEIDER ${ }^{20}$ parece ser a de maior praticabilidade, tendo sido já objeto de numerosas investigações ${ }^{1,24,6}$ 8. $10-14,18,19.29 .30$

Fato digno de nota, verificado pelo mencionado autor, foi o de que os camundongos infectados pelo vírus da raiva não revelavam presença deste agente nas glândulas salivares enquanto fosse negativo o teste de córnea.

O presente experimento tem por objetivo comparar a sensibilidade de duas técnicas para o diagnóstico precoce da raiva bovina: a técnica de imunofluorescência direta a partir de decalques de córnea e a de inoculação intracerebral de saliva em camundongos.

A hipótese de trabalho admitia que a técnica de imunofluorescência direta a partir de decalques de córnea apresentaria sensibilidade maior do que a de inoculação intracerebral de saliva em camundongos. Fixamos em 0,05 o nivel de rejeição da hipótese de nulidade.

\section{MATERIAL E MÉTODOS}

\section{BOVINOS}

Foram utilizados 18 bovinos azebuados, com idade entre 18 e 32 meses, apresentando sintomatologia de raiva decorrente da inoculação experimental.

\section{CAMUNDONGOS}

O sistema biológico empregado, tanto para o isolamento do vírus das amostras de saliva como, posteriormente, para o material proveniente de sistema nervoso central, foi representado por camundongos suíços albinos da linhagem CH3 Rockfeller, lactentes, com idade de sete a oito dias, e adultos, pesando 11 a 15 gramas, distribuídos em grupos de oito indivíduos. Cada grupo de camundongos lactentes era acompanhado da respectiva mãe.

\section{INÓCULO}

Inoculou-se suspensão a $20 \%$ de cérebro de camundongos infectados com vírus da raiva de origem bovina, amostra M. 95-60 NILSSON e cols. ${ }^{15}$ (1964), com título infectante igual a $10^{\text {no }}$ DL $50 / 0,3$ $\mathrm{ml}$. 


\section{DILUENTE}

No preparo da suspensão do vírus, bem como no tratamento da saliva, empregou-se água destilada contendo $2 \%$ de soro de equino normal, previamente inativado de $56^{\circ} \mathrm{C}$ durante 30 minutos, adicionada de 1.000 unidades de penicilina G Potássica e de 1,25 miligramas de sulfato de estreptomicina por mililitro. PROCEDIMENTOS

Os bovinos foram inoculados por via intramuscular na regiāo glútea, com cinco mililitros do inóculo acima descrito e, a seguir, mantidos sob cuidadosa observação até o aparecimento dos primeiros sintomas clínicos, caracterizados por: modificação de comportamento, tremores das grandes massas musculares do trem posterior, claudicação, incoordenação dos membros posteriores e mudança constante do pé de apoio (sinal de marcar passo), presente no início de todos os casos).

A partir da verificação dos sinais acima mencionados até a morte, procedeu-se, diariamente, para cada animal, à colheita de amostras de saliva e de córnea.

Cada amostra de saliva foi representada por cerca de três mililitros da secreção das glândulas salivares recolhida, por gravidade, em uma placa de Petri, ou, quando necessário, com o auxílio de seringas estéreis.

A saliva assim obtida foi adicionada de igual volume de diluente, mantida sob refrigeração em banho de gelo durante 30 minutos e a seguir inoculada, pela via intracerebral, num grupo de camundongos adultos na dose de $0,03 \mathrm{ml}$ e noutro de camundongos lactentes na dose de $0,01 \mathrm{ml}$ por animal. Estes animais foram observados por 30 dias, submetendo-se aos exames específicos para raiva (Sellers ${ }^{21}$, Imunofluorescência direta ${ }^{7}$ e Inoculação em camundongos ${ }^{28}$ ), os cérebros daqueles que apresentaram sintomas de doença ou sucumbiram a partir do quinto dia da inoculação.

As amostras de córnea foram colhidas com o emprego de lâminas apropriadas de microscopia, por decalques da córnea, utilizando-se quatro lâminas para cada um dos globos oculares e duas impressões por lâmina.
Tais decalques, após fixação em acetona a $-20^{\circ} \mathrm{C}$ - durante 24 horas, foram submetidos à técnica de imunofluorescência direta ${ }^{7}$, adotando-se como critérios de interpretação dos resultados aqueles utilizados por SCHNEIDER ${ }^{20}$ (1969) para o diagnóstico" "in vivo" da raiva em camundongos.

Todos os bovinos foram sacrificados na fase agônica e a seguir necropsiados. Os tecidos coletados para efeito de confirmação do diagnóstico consistiram de fragmentos de corno de Ammon, de cerebelo, de bulbo e de medula, utilizados para a realização dos exames específicos para o diagnóstico da raiva ${ }^{7.21 .28}$.

Os resultados obtidos foram analisados pelo teste de Mc Nemar, descrito por SIEGEL ${ }^{22}(1956)$.

\section{RESULTADOS}

Os resultados obtidos figuram nas tabelas I e II apresentadas a seguir.

$\mathrm{Na}$ tabela I estāo registrados, para cada um dos animais estudados, os resultados dos exames de córnea e de saliva, segundo o momento da realização do exame, expresso em dias, a partir do aparecimento dos sintomas clínicos.

As informações contidas nesta tabela indicam que o teste de córnea apresentou sempre maior freqüência de resultados positivos do que o teste praticado com a saliva durante todo o período de observação.

Realmente, os resultados dos exames de córnea realizados em dias sucessivos apresentaram valores percentuais crescentes, ao passo que os exames de saliva, realizados em paralelo, oscilaram.

Nota-se que o teste de córnea uma vez positivo manteve sempre esta característica, condição não verificada quando o material examinado foi saliva.

Acrescente-se ainda que em nenhum caso foi detectado vírus na saliva sem que se verificasse, para o mesmo animal, resultado positivo quando se empregou o teste de córnea.

Dentre os 18 animais observados, três não revelaram, com qualquer das técnicas empregadas e em momento algum da observação, a presença do vírus, não possibilitando, assim, o diagnóstico etiológico in vivo. 
TABELA I - RESULTADOS DOS EXAMES DE CÓRNEA E DE SALIVA DE BOVINOS COM RAIVA EXPERIMENTAL SEGUNDO O ANIMAL, O TIPO DE EXAME E O MOMENTO DE SUA REALIZACÃO EXPRESSO EM DIAS A PARTIR DO APARECIMENTO DOS SINTOMAS CLINICOS. SĀO PAULO, 1977.

\begin{tabular}{|c|c|c|c|c|c|c|c|c|c|c|}
\hline \multirow{2}{*}{$\begin{array}{c}\begin{array}{c}\text { MOMENTO DA } \\
\text { REALIZACÄO }\end{array} \\
\text { NATUREZADO EXAME } \\
\text { No DO ANIMAL }\end{array}$} & \multicolumn{2}{|c|}{1} & \multicolumn{2}{|c|}{ II } & \multicolumn{2}{|c|}{ III } & \multicolumn{2}{|c|}{ IV } & \multicolumn{2}{|c|}{ TOTAL } \\
\hline & C & S & C & $\mathbf{s}$ & C & $s$ & C & $s$ & C & s \\
\hline 007 & $\mathrm{~N}$ & $\mathbf{N}$ & $P$ & $N$ & $\mathbf{P}$ & $\mathbf{N}$ & $P$ & $\mathbf{N}$ & $3 / 4$ & $0 / 4$ \\
\hline 014 & $\mathbf{P}$ & $\mathbf{N}$ & $P$ & $\mathrm{~N}$ & NR & NR & NR & NR & $2 / 2$ & $0 / 2$ \\
\hline 015 & $P$ & $\mathbf{P}$ & $\mathbf{P}$ & $\mathrm{N}$ & $\mathbf{P}$ & $\mathbf{N}$ & $P$ & $\mathrm{~N}$ & $4 / 4$ & $1 / 4$ \\
\hline 017 & $\mathbf{N}$ & $\mathbf{N}$ & $\mathbf{N}$ & $N$ & $N$ & $\mathrm{~N}$ & NR & NA & $0 / 3$ & $0 / 3$ \\
\hline 018 & $P$ & $\mathbf{N}$ & $P$ & $\mathbf{N}$ & $\mathbf{P}$ & $N$ & $\mathbf{P}$ & $P$ & $4 / 4$ & $1 / 4$ \\
\hline 023 & $P$ & $\mathbf{P}$ & $\mathbf{P}$ & $\mathbf{P}$ & $\mathbf{P}$ & $N$ & $P$ & $N$ & $4 / 4$ & $2 / 4$ \\
\hline 024 & $P$ & $\mathbf{N}$ & $P$ & $\mathbf{N}$ & NR & NR & NR & NR & $2 / 2$ & $0 / 2$ \\
\hline 029 & $\mathbf{P}$ & $\mathbf{N}$ & $\mathbf{P}$ & $\mathbf{P}$ & NR & NR & NR & NR & $2 / 2$ & $1 / 2$ \\
\hline 034 & $P$ & $N$ & $\mathrm{P}$ & $\mathrm{N}$ & NR & NR & NR & NR & $2 / 2$ & $0 / 2$ \\
\hline 037 & $P$ & $\mathbf{N}$ & $\mathbf{P}$ & $\mathbf{N}$ & $\mathbf{P}$ & $\mathbf{N}$ & $\mathrm{P}$ & $\mathbf{P}$ & $4 / 4$ & $1 / 4$ \\
\hline 040 & $\mathbf{P}$ & $\mathbf{N}$ & $\mathbf{P}$ & $\mathbf{N}$ & $\mathbf{P}$ & $P$ & $\mathbf{P}$ & $\mathrm{N}$ & $4 / 4$ & $1 / 4$ \\
\hline 041 & $N$ & $\mathbf{N}$ & $\mathbf{P}$ & $\mathbf{N}$ & NR & NR & NR & NR & $0 / 2$ & $0 / 2$ \\
\hline 043 & $P$ & $P$ & $\mathbf{N}$ & $P$ & $\mathbf{P}$ & $\mathbf{N}$ & NR & NR & $3 / 3$ & $2 / 3$ \\
\hline 046 & $\mathbf{P}$ & $\mathbf{N}$ & $\mathbf{P}$ & $\mathrm{N}$ & $\mathbf{P}$ & $\mathrm{N}$ & $\mathbf{P}$ & $\mathbf{N}$ & $4 / 4$ & $0 / 4$ \\
\hline 047 & $\mathbf{P}$ & $\mathbf{P}$ & $\mathbf{P}$ & $\mathbf{N}$ & $\mathbf{P}$ & $\mathbf{N}$ & $\mathbf{P}$ & $\mathrm{N}$ & $4 / 4$ & $1 / 4$ \\
\hline 048 & $P$ & $P$ & $P$ & $\mathbf{P}$ & $\mathbf{P}$ & $\mathbf{N}$ & $P$ & $P$ & $4 / 4$ & $3 / 4$ \\
\hline 052 & $\mathbf{P}$ & $\mathbf{N}$ & $\mathbf{P}$ & $N$ & NR & NR & NA & NR & $2 / 2$ & $0 / 2$ \\
\hline 055 & $\mathrm{~N}$ & $\mathbf{N}$ & $\mathbf{N}$ & $\mathrm{N}$ & $\mathbf{N}$ & $\mathbf{N}$ & NR & NR & $0 / 3$ & $0 / 3$ \\
\hline TOTAL & $14 / 18$ & $5 / 18$ & & $4 / 18$ & $10 / 12$ & $1 / 12$ & $9 / 9$ & $3 / 9$ & $48 / 57$ & $13 / 57$ \\
\hline$\%$ POSITIVO & 77,7 & 27,7 & & 22,2 & 83,3 & 8,3 & 100.0 & 33,3 & 84,2 & 22,8 \\
\hline
\end{tabular}

C-CORNEA P-POSITIVO NR-NÁO REALIZADO (MORTE DO ANIMAL)

\section{S-SALIVA N-NEGATIVO}

$E$ de salientar-se, finalmente, que nos 57 pares de amostras examinados (córnea e saliva) a freqüência de reações positivas, quando se empregou uma e outra técnica, foi marcadamente diferente: $84,2 \%$ com a técnica de imunofluorescência direta aplicada à córnea e $22,8 \%$ com a de inoculação de camundongos a partir da saliva.

Este fato é colocado em evidência na tabela II.

TABELA II - EXAMES DE LABORATORIO SEGUNDO O TIPO DE MATERIAL COLHIDO DURANTE A FASE CLINICA DA RAIVA EXPERIMENTAL EM BOVINOS E A NATUREZA DO RESULTADO. 1977.

\begin{tabular}{|c|r|r|r|}
\hline SALIVA & NEG. & POS. & TOTAL \\
\hline CORNEA & & & \\
\hline POSITIVO & 35 & 13 & 48 \\
\hline NEGATIVO & 9 & 0 & 9 \\
\hline TOTAL & 44 & 13 & 57 \\
\hline
\end{tabular}

A observação desta tabela indica a existência de 35 resultados discordantes dentre os 57 pares de amostras examinadas por ambas as técnicas.

Esses 35 resultados foram positivos com a técnica de imunofluorescência direta aplicada a decalques de córnea e negativos com a de inoculação intracerebral em camundongos feita a partir de saliva.

Diante destes resultados resolveuse testar a hipótese de nulidade segundo a qual a freqüência de resultados positivos com a técnica de imunofluorescência direta aplicada a decalques de córnea não difere significantemente da freqüência de resultados positivos alcançados com a técnica de inoculação intracerebral em camundongos empregando-se saliva ou, em outras palavras, que ambas as técnicas são equivalentes para fins de diagnóstico etiológico precoce da raiva bovina, ou ainda, que ambas as técnicas apresentam igual sensibilidade. 
A hipótese alternativa, estabelecida, também, antes do início do experimento, era de que a freqüência de resultados positivos obtidos com a técnica de imunofluorescência direta aplicada a decalques de córnea é superior à que se obtém com a técnica de inoculação intracerebral em camundongos a partir da saliva.

Para o teste de hipóteses, procedeu-se ao tratamento estatístico dos dados pela técnica de McNemar, descrito por SIEGEL ${ }^{22}$, encontrando-se para o $\mathrm{X}^{2}$ o valor 33,028 que, comparado ao valor crítico desta estatística para 1 grau de liberdade e para o nivel de rejeição adotado, igual a 0,05 , mostrou-se significante, permitindo, portanto, rejeitar a hipótese de nulidade, aceitando-se a hipótese alternativa segundo a qual a freqüência de resultados positivos com a técnica de imunofluorescência direta aplicada à córnea é significantemente maior que a constatada com a técnica de inoculação intracerebral em camundongos feita a partir de saliva. Em outras palavras, pode-se dizer que a primeira das técnicas é significantemente mais sensivel que a segunda.

Os exames realizados com as amostras de tecido nervoso revelaram, para todos os bovinos estudados, resultados positivos aos testes específicos para o diagnóstico da raiva ${ }^{7,}{ }^{21,}{ }^{28}$.

\section{DISCUSSAO}

Os dados obtidos e o resultado da análise estatística realizada realçam a importância da técnica de imunofluorescência direta aplicada a decalques de córnea para diagnóstico etiológico in vivo da raiva em bovinos.

De fato, os valores da tabela I mostram que, por ocasião do aparecimento dos sintomas clínicos da doença, 14 dos 18 animais estudados $(77,7 \%)$ apresentaram resultado positivo com essa técnica. Nos dias subseqüentes, os valores positivos foram, respectivamente, $15 / 18(83,3 \%) ; 10 / 12(83,3 \%)$ e $9 / 9$ $(100 \%)$.

Os elementos desta tabela indicam ainda que, uma vez presente na córnea, o antígeno rábico aí permanece, eviden- ciável pela técnica de imunofluorescência direta, até a morte do animal. Tal observação assume destacada importância quando se pretende utilizar esta técnica para o diagnóstico etiológico precoce da raiva em bovinos.

Convém ressaltar, contudo, que dos 18 animais utilizados, três (os animais de números 017,041 e 055 ) não revelaram a presença de vírus na córnea, em momento algum do período de observação, mostrando a ocorrência de resultados falso-negativos em $16,7 \%$ dos bovinos. Este aspecto foi também assinalado por ZIMMERMANN ${ }^{30}$ (1971) que examinando, com a mesma técnica, seis bovinos acometidos pela raiva, em condições naturais, encontrou apenas três casos positivos.

Ainda com base nos dados da tabela I verifica-se que o exame da saliva pela técnica de inoculação intracerebral em camundongos mostrou-se pouco sensível como elemento de diagnóstico precoce da doença. Realmente, apenas cinco dos 18 animais utilizados $(27,7 \%)$ apresentaram vírus na saliva, demonstrável com esta técnica, por ocasião do aparecimento dos sintomas da doença. Nos dias subseqüentes, tais resultados foram, respectivamente, $4 / 18(22,2 \%)$, $1 / 12(8,3 \%)$ e $3 / 9(33,3 \%)$. É preciso consignar, ainda, a inconstância com que, para o mesmo animal, o vírus pôde ser demonstrado na saliva durante o período de observação, e a freqüência de resultados falso-negativos com esta técnica, igual a $50 \%$. De fato, os animais de números $007,014,017,024,034,041$, 046,052 e 055 jamais revelaram a presença do vírus na saliva.

Em síntese, o presente estudo revela que a técnica de imunofluorescência direta aplicada a decalques de córnea apresentou maior freqüência e constância de resultados positivos do que a técnica de inoculação intracerebral em camundongos feita a partir da saliva.

Realmente, analisados os dados da tabela II pela técnica de McNemar obteve-se para $\mathrm{X}^{2}$ um valor 33,028 que comparado ao valor crítico desta estatística para 1 grau de liberdade mostrou-se significante ao nivel de rejeição adotado, caracterizando maior sensibilidade da 
técnica de imunofluorescência direta aplicada a decalques de córnea comparativamente à técnica de inoculação intracerebral em camundongos a partir da saliva.

Os dados desta tabela mostram ainda que, dos 35 pares de amostras (córnea e saliva) com resultados discordantes, nenhum deles apresentou resultado positivo à técnica de inoculação intracerebral em camundongos a partir da saliva, quando foi negativo o exame de córnea, pela técnica de imunofluorescência direta.

Estas observações não concordam com as de MOREIRA e REIS'14 que utilizando quatro bezerros com raiva experimental obtiveram resultados negativos em todos os exames realizados com a técnica de imunofluorescência direta aplicada a decalques de córnea e positivos com a técnica de inoculação intracerebral em camundongos a partir da saliva, mas corroboram às de outros pesquisadores que observaram igual comportamento em outras espécies animais. É o caso de SCHNEIDER ${ }^{20}$ que utilizou camundongos e de KOVALEV e SHASHEN'KO" que se valeram de ovinos e coelhos.

A maior sensibilidade da técnica de imunofluorescência direta aplicada à córnea, aliada à maior facilidade de colheita de material, à menor exposição do operador ao risco de infecção, e, notadamente, a substancial redução que se consegue no tempo necessário para a obtenção dos resultados, fazem desta prova valioso instrumento para o diagnóstico precoce da raiva, quando comparada à técnica de inoculação intracerebral da saliva em camundongos.

\section{AGRADECIMENTOS}

Para o planejamento e execução deste trabalho contamos com a colaboração do Professor Doutor Adolpho Ribeiro Netto, ao qual consignamos o nosso agradecimento e profunda gratidão.

Agradecemos ainda ao Doutor Ioshihiro Otsubo e a Dna. Maria Luiza Rigo Pasquarelli pela colaboração que nos emprestaram.

RFMV-A/18

CÔRTES, J.A.; NILSSON, M.R.; VASCONCELLOS, S.A. Comparative studies on sensitivity of the cornea examination by direct fluorescent antibody technique and intracerebral mice inoculation with saliva to the intravitam diagnosis of experimental rabies in cattle. Rev. Fac. Med. Vet. Zootec. Univ. S.Paulo, 15 (2):-, 143-50, 1978 .

SUMMARY: The examination of 57 samples pairs (cornea and saliva) collected from 18 bovines with experimental rabies by both techiniques direct fluorescent antibodies applied to cornea impressions and intracerebral mice inoculation with saliva revealed that the former provided a greater frequency of positive reactions $(84,2 \%)$ than the latter $(22,8 \%)$. In addition, it was observed that once the cornea test had provided a positive result such condi tion was mantained until death of the animal, and in no occasion could the virus be detected in saliva without a positive result with the cornea test on the same animal. The false negative values obtained with the cornea test $(16,7 \%)$ suggested that a negative result does not exclude the possibility of the disease.

UNITERMS: Rabies, bovines; Cornea, test*; Saliva, examination".

\section{REFERÊNCIAS BIBLIOGRÁFICAS}

1 - ATANASIU, P.; GUILlON, J.C; VALLÉE, A. Contribution a l'étude de la rage expérimentale du renard Ann. Inst. Pasteur, Paris, 119: 260-9, 1970

2 - Balasubramanian, A. GAJANA. NA, A.; MARIASUSAI, M.; SIVANAN JAN, L.; DEVARAJ, R.; GASS, M.E. The value of corneal test in the diagnosis of rabies. In: PASTEUR INSTITUTE OF SOUTHERN
OF INDIA, Condnnor. Annual Report of the Director: $1972 / 73$, p.45

3 - BALASUBRAMANIAN, A.; GAJANANA, A.; MARIASUSAI, M.: SIVANAN JAN, L.; DEVARAJ, R.; GASS, M.E. Studies on the salivary excretion of rabies virus in the dog "Andi" that bit case 12. Sci Rep. Pasteur Inst. sth. India, 1974, p.44 
4-BESEDA, M. Reability of the corneal test in the diagnosis of rabies: comparative studies. Vet. Cas., 14(4): 121-3, 1972.

5 - BRYCESON, A.D.M.; GREENWOOD, B.M.; WARREL, D.A.; DAVIDSON, N.M.; POPE, H.M.; LAWRIE, J.H.; BARNES, H.J. ; BAILIE, W.E.; WILCOX, G.E. Demonstration during life of rabies antigen in humans $J$. infect. Dis., 131 (1): 71-4, 1975.

6-CIFUENTES, E.; CALDERON, E.; BIJLENGA, G. Rabies in a child diagnosed by a new intra-vitam method. The cornea test.J.trop.Med. Hyg. 74: 23-5, 1971.

7 -GOLDWASSER, R.A. \& KISSLING, R.E.Fluorescent antibody staining of street and fixed rabies virus antigens. Proc. Soc. exp. Biol.Med.,98 (2): 21923, 1958.

8 - HORYNA, B. \& KABELIK, V. Verification of the corneal test on laboratory animals for the diagnosis of rabies in animals during life. Veterinarni Medicina, 18(7): 449-54, 1973.

9 - KAPLAN, M.M. Evaluacion de las tecnicas de laboratorio aplicables al diagnostico y la prevencion de rabia y las investigaciones antirrabicas. In: ORGANIZACION MUNDIAL DE LA SALUD. La rabia. Tecnicas de laboratório. 3.ed. Ginebra, 1976. p.19-26.

10 - KOCH, J.L.; SAGARTZ, J.W.; DAVIDSON, D.E.; LAWHASWASDI, K. Diagnosis of human rabies by the cornea test. Amer.J. clin. Path., 63(4): 509-15, 1975.

11 - KOVALEV, N.A. \& SHASHEN'KO A.S. Immunofluorescent examination of corneal impression smears for rabies. Veterinariya, Moscow, 9: 44-6, 1970.

12 - LARGHI, O.P.; GONZÁLEZ, E.; HELD, J.R. Evaluation of the corneal test as a laboratory method for rabies diagnosis. Appl. Microbiol., 25 (2): $187-9,1973$.

13 - LOPEZ, J.A.; ALVAREZ, J ; GIL, J.L. Diagnostico in vivo de la rabia humana por immunofluorescencia en cornea. Antioquia med., 20 (9/10): 577-82, 1970.

14 - MOREIRA, E.C.\& REIS, R. Pesquisa do virus da raiva no humor aquoso, saliva, glândulas salivares submaxilares e cornea de bezerros inoculados experimentalmente. Arq.Esc. Vet. Minas Ge rais, $27(3)$ : 335-49, 1975.

15 - NILSSON, M.R.; SUGAY, W.; CARVALHO, C.L.S. Consideraçōes sobre um virus rábico de curto período de incubaçāo, isolado de bovino. Arq. Inst. Biol; São Paulo, 31 (4): 113-8, 1964.

16 - NILSSON, M.R. Revisāo do conceito de que raiva é sempre fatal. Bol. Of.sanit. panamer, 68 (I): 486-94, 1970.

17 - PAWAN, J.L. Infectivity of the saliva in paralytic rabies. Ann.trop. Med.
Parasit., 31: 267-70, 1937

18 - REIS, R.; FIGUEIREDO, J.B.; MOREIRA, E.C. NEVES, J.; GONTIJO, M.T.; ORNELAS-SANTOS, P.P. Presença do vírus rábico na córnea, humor aquoso e nervo óptico de humanos, bovinos, felinos e caninos com raiva. Arq. Esc.Vet. Minas Gerais, 23: 207-14, 1971

19 - SCHAAF, J. \& SCHAAL, E. Diagnostic value of the cornea test, the nose test and the mouth test for diagnosing rabies when carried out on rabiespositive post-mortem material.Dtsch. tierarztl. Wschr., 78: 341-6, 1971.

20 - SCHNEIDER, L.G. The cornea test; new method for the intra-vitam diagnosis of rabies. $\mathrm{Zbl}$. Vet. Med. B., 16 (1): 24-31, 1969.

21 - SELLERS, F.F. A new method for staining negri bodies of rabies. Amer. J.publ. Hlth, 17: 1080-1, 1927.

22 - SIEGEL, S. Nonparametric statistics for the behavioral sciences. New York McGraw-Hill, 1956. 312p.

23 - SMITH, W.B.; BLENDEN, D.C.; FUH T.H.; HILER, L.Diagnosis of rabies by immunofluorescent staining of frozen sections of skin. J.Amer. vet.med. Ass., 161 (11): 1495-501, 1972.

24 - VALLONE, E.F.; VALLONE, R.M.C. BAUZÁ, C.A.; TOSI, H.C. Rabia humana. Diagnostico pré-mortem a partir de la saliva por inmunofluorescencia. Arch. Pediat., Uruguay, 37: $563-7,1966$

25 - VAUGHN, J.B.; GERHARDT, P.; PA TERSON, J.C.S. Excretion of street rabies virus in saliva of cats. J.Amer, med.Ass., 184(9): 119-22, 1963.

26 - VAUGHN, J.B.; GERHARDT, P.; NE WELL, K.W. Excretion of streee rabies virus in the saliva of dogs. $J$. Amer.med. Ass., 193 (5): 113-8, 1965.

27 - VEERARAGHAVAN, N.; GAJANANA A.; RANGASSAMI, R.; CONNUN. NI, P.T.; SARASWATHI, K.C. DEVARAJ, R.; HALAN, K.M. Studies on the salivary excretion of rabies virus by the dog from Surandai. Sci. Rep. Pasteur Inst. sth. India, 1969. p. 66.

28 - WEBSTER, L.T. \& DAWSON, J.R. Early diagnosis of rabies by mouse inoculation. Measurement of humoral immunity to rabies by mouse protec tion test. Proc. Soc. exp. Biol.Med. 32: $570-3,1935$.

29 - WIEGAND, D. Comparative investiga tions of the significance of the corneal test in rabies diagnosis. Arch. exp. Vet. Med, 29 (3): 323-30, 1975

30 - ZIMMERMAN, T. The aplicability of the cornea test in rabies diagnosis. Berl. Munch. tierarztl. Wschr. 84 (9): 172-4, 1971.

Aprovado para publicaçto em $4-9-1978$ 